Sādhanā Vol. 38, Part 5, October 2013, pp. 999-1025. (C) Indian Academy of Sciences

\title{
Integrated safety assessment of Indian nuclear power plants for extreme events: Reducing impact on public mind
}

\author{
ANIL KAKODKAR ${ }^{1, *}$ and RAM KUMAR SINGH ${ }^{2}$ \\ ${ }^{1}$ Bhabha Atomic Research Centre, Trombay, Mumbai 400 085, India \\ ${ }^{2}$ Reactor Safety Division, Bhabha Atomic Research Centre, Trombay, Mumbai \\ 400 085, India \\ e-mail:kakodkar@barc.gov.in, kakodkaranil@gmail.com; \\ rksingh@barc.gov.in,rksingh175@rediffmail.com
}

\begin{abstract}
Nuclear energy professionals need to understand and address the catastrophe syndrome that of late seems to be increasingly at work in public mind in the context of nuclear energy. Classically the nuclear power reactor design and system evolution has been based on the logic of minimization of risk to an acceptable level and its quantification based on a deterministic approach and backed up by a further assessment based on the probabilistic methodology. However, in spite of minimization of risk, the reasons for anxiety and trauma in public mind that still prevails in the context of severe accidents needs to be understood and addressed. Margins between maximum credible accidents factored in the design and the ultimate load withstanding capacities of relevant systems need to be enhanced and guaranteed with a view to minimize release of radioactivity and avoid serious impact in public domain. A more realistic basis for management of an accident in public domain also needs to be quantified for this purpose. Assurance to public on limiting the consequences to a level that does not lead to a trauma is something that we need to be able to credibly demonstrate and confirm. The findings from Chernobyl reports point to significant psychological effects and related health disorders due to large scale emergency relocation of people that could have been possibly reduced by an order of magnitude without significant additional safety detriment. A combination of probabilistic and deterministic approaches should be evolved further to minimize consequences in public domain through enhancing safety margins and adding greater precision to quantitatively predicting accident progression and its management. The paper presents the case studies of the extreme external event such as tsunami and its impact on the coastal nuclear plants in India, the containment integrity assessment under the extreme internal event of over-pressurization and aircraft impact along with hydrogen deflagration/detonation-induced loadings. These are at the moment extremely burning issues due to the severe accidents of Fukushima, Chernobyl and Three Mile Island reactors. In the present day context identifying the extreme loadings in a separate category and the corresponding margin assessment is necessary in addition to
\end{abstract}

${ }^{*}$ For correspondence 
the implementation of the mitigation and upgraded safety measures. Further, the paper attempts to address the question of public trauma in the event of a serious nuclear reactor accident, a need that has been felt in view of the recent Fukushima and earlier Chernobyl accidents and the resulting large scale relocation due to the present deficient policies and the inherent limitations of Linear No Threshold (LNT) principle.

Keywords. Nuclear reactor safety; extreme events; three mile island accident; chernobyl accident; Fukushima accident; earthquake; tsunami; nuclear containment; pressurized heavy water rector; aircraft impact; hydrogen deflagration \& detonation; radiation dose; linear no threshold (LNT); public trauma.

\section{Introduction}

In the history of mankind, introduction of new technologies for societal benefits has always been challenging. Ability to deal with the fear of unknown and the perception of man-made as also natural disasters linked with the new technologies have influenced the growth of societies and nations. Despite the setbacks caused by some extreme events linked to a new technology, the technologists, governmental bodies, professional societies and non-governmental organizations in the emerging and progressive nations have displayed greater maturity to effectively address the risk and threat perception. On the basis of demonstration of safety, assurance of sustainable growth potential and relative economic benefits, they have managed to restore public confidence in promising new technologies. Large scale evacuation of people in the aftermath of the extreme external natural event-induced accident in Fukushima in 2011 and earlier similar experience of public in the context of severe accident at Chernobyl in 1986 have resulted in trauma in public mind and perhaps avoidable psychological effects described by Havenaar et al (1997); that need to be understood and addressed besides the demonstration of safety and economy of Indian Nuclear Power Plants for extreme external and internal events.

Earlier, the progression of two severe accidents at Three Mile Island-1979 (USA) and Chernobyl-1986 (former USSR) nuclear reactors; highlighted the importance of internal events. These accidents have been widely studied and analysed and that led to improved operations and safety culture as well as evolution of new generation/advanced reactor systems. These sustained efforts did restore confidence in nuclear power which had in fact started showing significant signs of renaissance. The recent severe accident at Fukushima in (2011) multiple nuclear units originated from extreme natural events of earthquake and tsunami external to the plant, escalating further into induced internal severe damage sequences and consequential large scale evacuation of people. The experience gained from these three accidents shows that a comprehensive approach towards minimizing the impact in public domain through limiting the severity of the accident and its optimal management needs to be evolved. It is necessary to minimize the need for large scale evacuation of people through a systematic evolution of (i) a defined credible limit on the extreme external events such as tsunamis and earthquakes for specific regions/sites and specification of a stringent siting criteria, (ii) the necessary safety upgrades for the existing nuclear plants and robust design of new reactor systems with systematic deterministic design and safety evaluation backed up with the probabilistic assessment of nuclear reactor structures, systems and components and (iii) the appropriate intervention level to minimize the public trauma and overcome the inherent limitations of the present dose levels, which are based on Linear No-Threshold (LNT). This LNT principle has been subject of intensive debate as reported by Bodansky (2004), Jaworowski (2010) and recently after the Fukushima event by Calabrese 
(2011a, b) and Kakodkar (2011). All the above identified three steps are essential to minimize the impact in the public domain and early restoration of the nuclear power plant. Availability of nuclear electricity in case of extreme natural and other manmade events could be effectively utilized for more efficient post event normalcy restoration and this will in turn help to minimise trauma caused by such events.

Buongio et al (2011) in the Massachusetts Institute of Technology (MIT) report have summarized the technical lessons learnt from Fukushima event under the following categories (i) Emergency power following beyond design basis external events, (ii) emergency response to beyond design basis external events, (iii) containment, (iv) hydrogen management, (v) spent fuel pools and (vi) plant siting and site layout. This list is just and an indicative and the nuclear plant safety needs to be looked at holistically by designers, plant operators, regulators and R\&D experts in a comprehensive manner.

In the context of Indian nuclear power plants, the integrated safety assessment has been carried out through a large number of experimental programs, round robin exercises, benchmarks and standard problem exercises. A few case studies of extreme external and internal events with regard to tsunami assessment of Indian Nuclear Power Plants (NPPs), PHWR containment ultimate load capacity assessment on BARC Containment (BARCOM) Test Model and air-craft impact assessment, are described in this paper. Also presented are the case studies related to hydrogen load characterization, its effective management and enclosure structure performance for Indian NPPs.

Based on the studies for these extreme events, recommendations are given for an integral safety assessment and the public trauma is addressed in a scientific manner with an objective to reinforce the sustainable growth of nuclear power for the benefit of Indian society.

\section{Extreme earthquakes and tsunamis and Indian coastal nuclear plants}

Besides the design basis earthquakes, tsunamis, storm surges, hurricanes, heavy precipitation and other natural events, the extreme earthquakes and tsunamis have been of special interest for Indian coastal nuclear facilities after the 2004 tsunami event in Indian Ocean. The tsunami source term characterization with the details of fault parameters, propagation analysis to obtain the tsunami wave height and wave arrival time through global modelling, inundation modelling based on a refined local bathymetry and land morphology and validation of the numerical code with post tsunami survey data, tide gauge records and historical tsunami data are the important steps for the qualification of a tsunami mathematical model. The tsunami event of 26th December 2004 due to Sumatra earthquake and the resulting inundation at Kalpakkam was efficiently managed by Department of Atomic Energy (DAE) at the Madras Atomic Power Station (MAPS), the upcoming Prototype Fast Breeder Reactor and the township areas. In view of the observed inundation, a need was felt for the detailed evaluation of the present and future coastal nuclear sites for the extreme tsunami and earthquake events and the in-depth studies were initiated as reported in DAE Committee reports by Sasidhar et al $(2009,2012)$ and papers by Singh et al (2008), Singh \& Kushwaha (2009, 2010) and Singh (2011a, 2012a, b).

In Indian Ocean, the tsunami historical data is limited; however, the mega tsunami event of December 26, 2004 resulting from Sumatra earthquake of magnitude 9.3 is well-studied, recorded and instrumented. Further, the events of submarine earthquakes of 28 March 2005 of magnitude 8.6, July 17, 2006 of magnitude 7.7 and September 12/13, 2007 of magnitudes 8.5/7.9 in Indian Ocean region have been analysed by seismologists and oceanographers. The National Warning System has been in place and the earthquake events and the tide gauge data are 
Chennai 13.10 N 80.30 E 11/04/2012 12:00 0.18m

Vizag 17.71 N 83.32 E 11/04/2012 12:14 0.10m

Ennore 13.25 N 80.33 E 11/04/2012 12:04 0.09m

Meulaboh 4.317 N 96.217 E 11/04/2012 09:51 1.06m

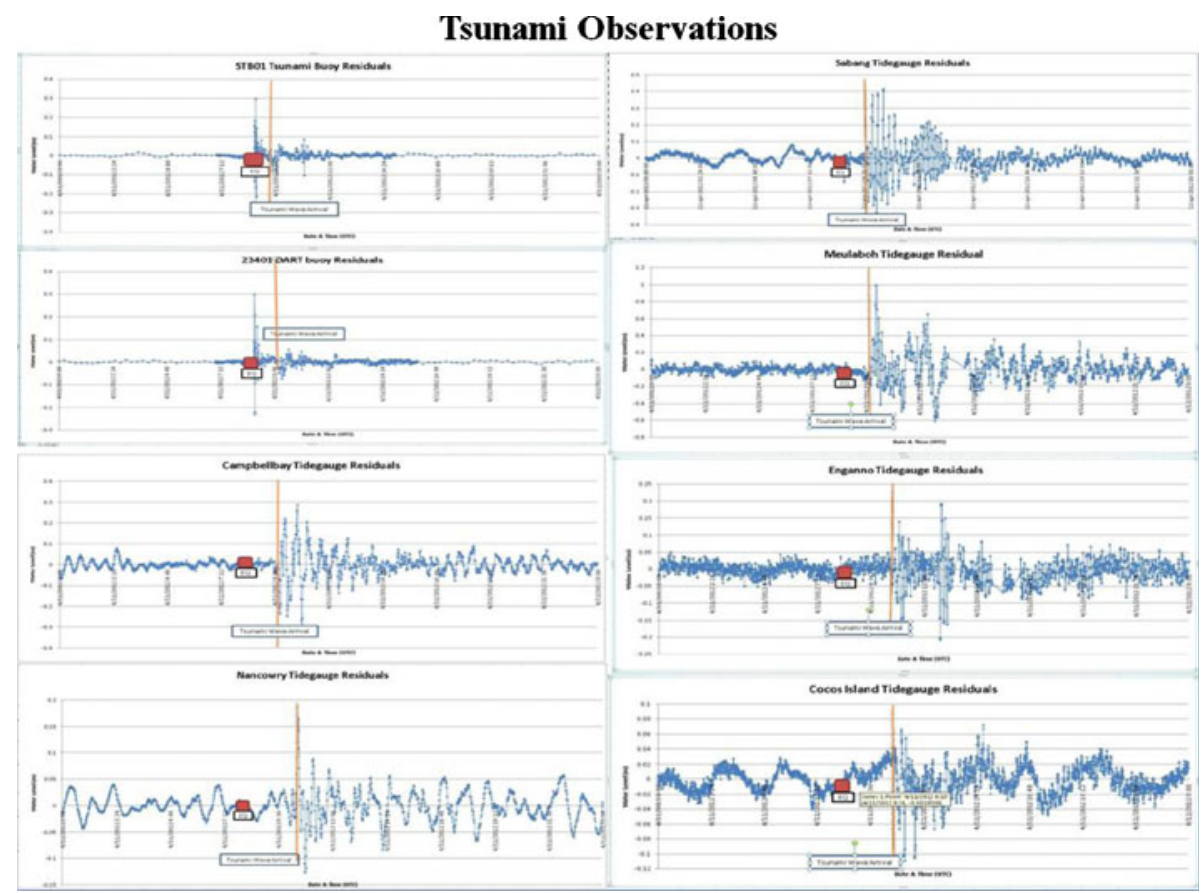

Figure 1. Tsunami observation for April 11, 2012 of Sumatra earthquake event (Srinivasa Kumar et al 2012).

being continuously recorded and analysed in a regular manner. During the recent Sumatra earthquake event of April 11, 2012, the initial magnitude of the earthquake was estimated $\sim 8.7$ on the Richter scale. As reported by Indian National Centre for Ocean Information Services (INCOIS), the first bulletin was issued within 8 minutes at 14-16 h IST. The earthquake magnitude estimate was later revised to 8.5. This earthquake could have been tsunamigenic and the response and preparedness of plants was further critically examined. All the systems for the identification of location of earthquake, estimation of tsunami arrival time and wave height, dissemination of messages through SMS, email, Fax, GTS \& Website, as well as bottom pressure recorders and tidal gauges to record sea level changes managed under the National Warning System have performed as envisaged (Srinivasa Kumar et al (2012) as can be seen in figure 1). The information regarding earthquake and tsunami alert was received in MAPS, Kalpakkam Control Room simultaneously with local warning system and from National Agencies immediately after the event. The emergency response and the precautionary measures as per the operating procedures were initiated and readiness of all systems to handle the probable tsunami was ensured.

A comprehensive tsunami evaluation has been made for the present and future prospective Indian coastal sites with a further backup safety review of Indian nuclear power plants after the recent accident in the Japanese nuclear plants at Fukushima Daichi due to the extreme event 


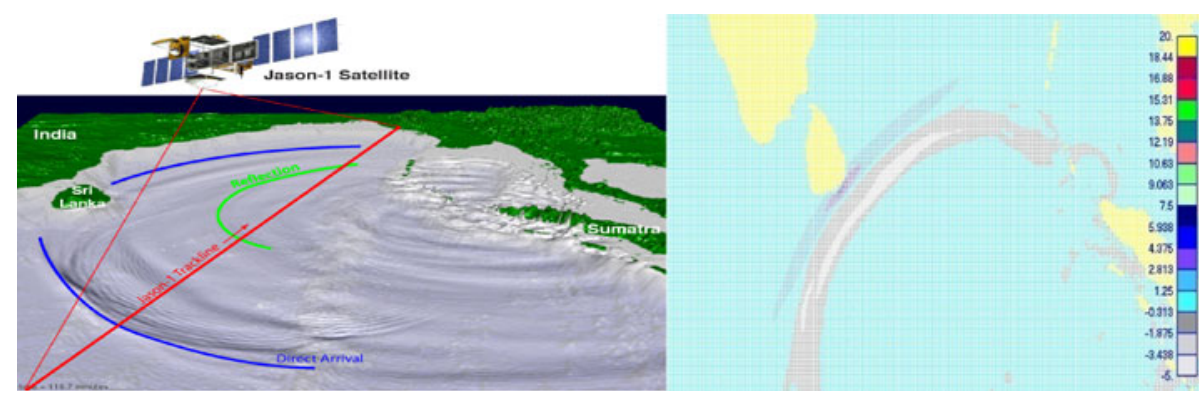

Figure 2. JASON-1 Track 109 Satellite (altitude $1300 \mathrm{~km}$ ) Record and TSUSOL Predictions.

of 11 March 2011 Tohoku Earthquake and Tsunami on the Pacific Coast of Eastern Japan as presented in Singh (2011a, 2012a and b). In this section of the present paper, the findings of the tsunami assessment for all the coastal nuclear plants and a comparative study is presented for the upcoming Kudankulam plant with regard to the Fukushima Daichi plant tsunami inundation resulting into the severe accident.

\section{Tsunami evaluation of Indian coastal sites}

The two tsunami events, one due to Sumatra earthquake with magnitude 9.3 of December 26, 2004 and the other due to Makran earthquake with magnitude 8.1 of November 28, 1945 are of interest for the present and future prospective nuclear coastal sites of India. The site selection and
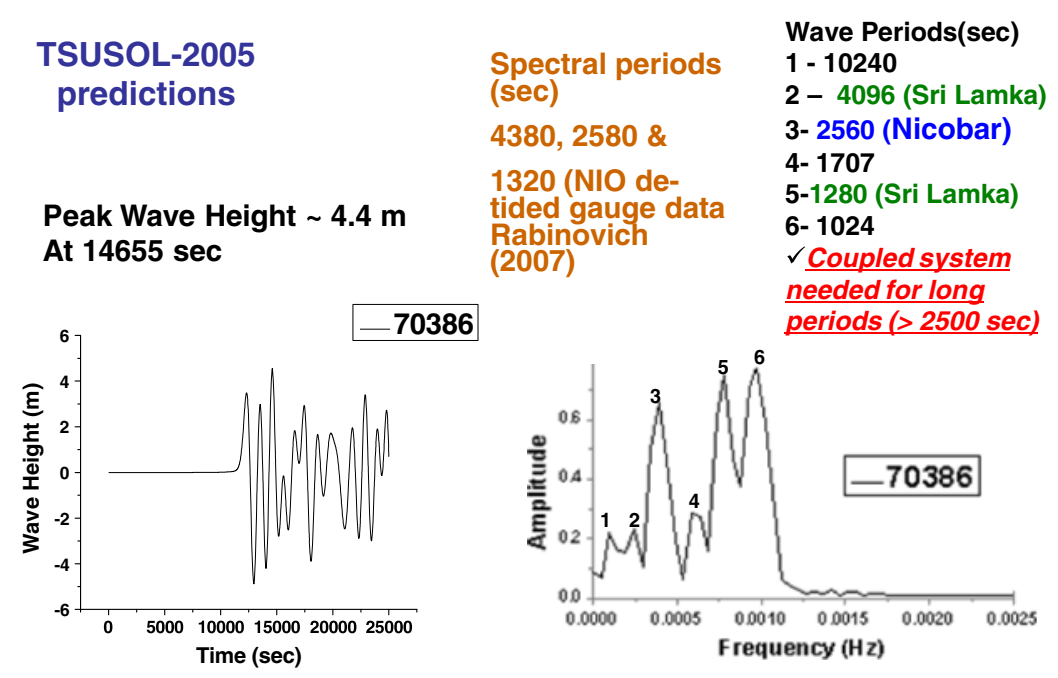

Typical Time Signal at South Indian Coast Multiple Wave Periods due to Wave Scattering and Reflections from Sri Lanka Sumatra event was a far field event and hence decoupled analysis justified with static boottom displacement model as evident here (R K Singh, BARC, INDIA)

Figure 3. Spectral analysis of tsunami waves from TSUSOL predictions for Sumatra event 2004 and comparison with NIO tide gauge data. 


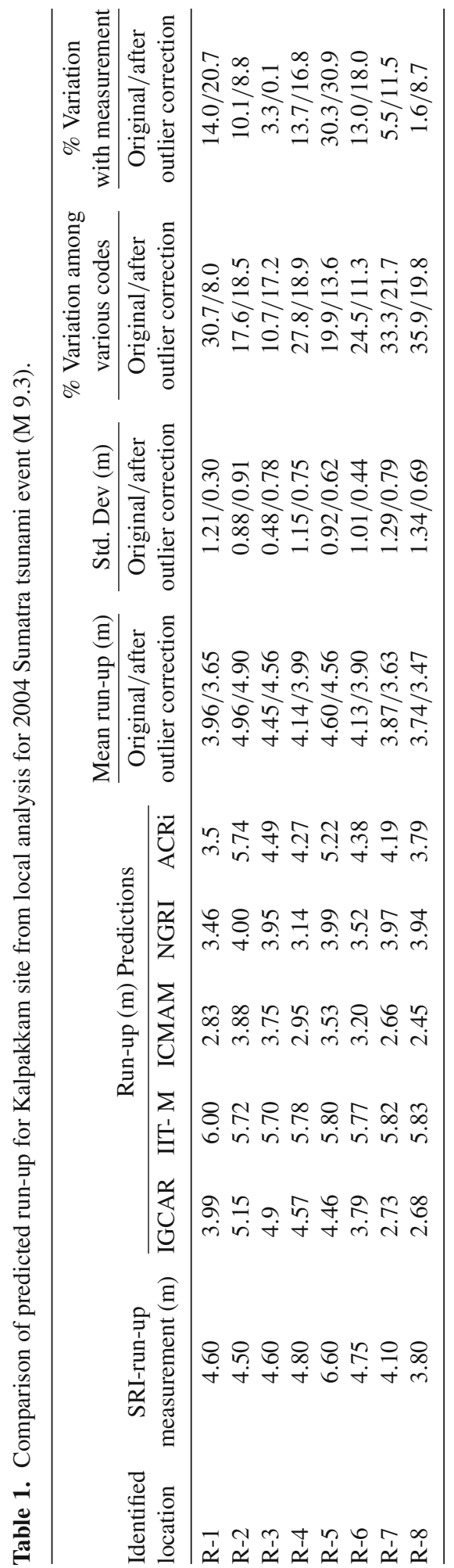



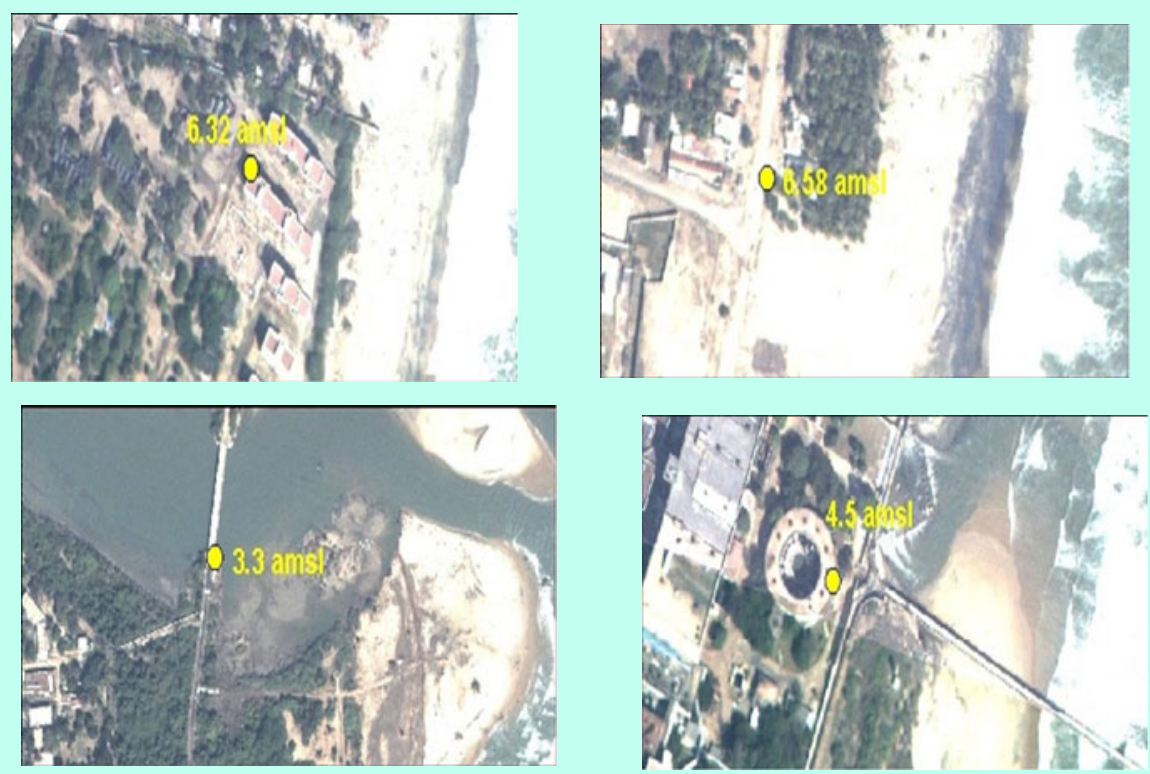

R1 Edaiyur Bridge

R2 Water Intake MAPS

R5 Sadras Fort

R6 Township, Sadras East

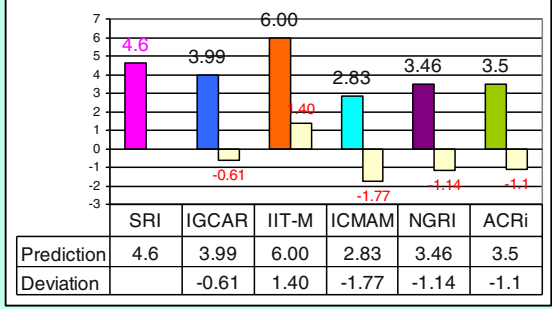

R-1 Edaiyur Bridge

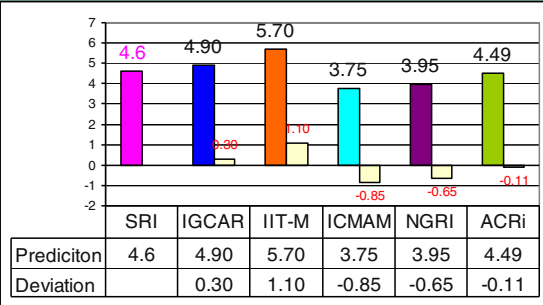

R-3 BHAVINI soil sample storage building

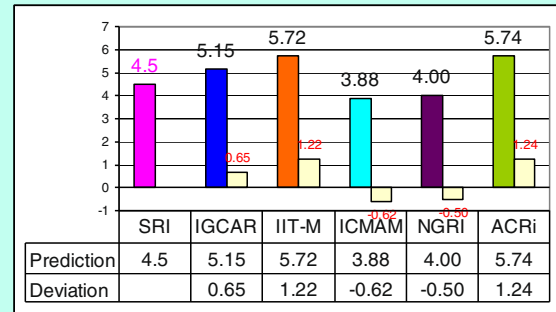

R-2 Water intake - MAPS

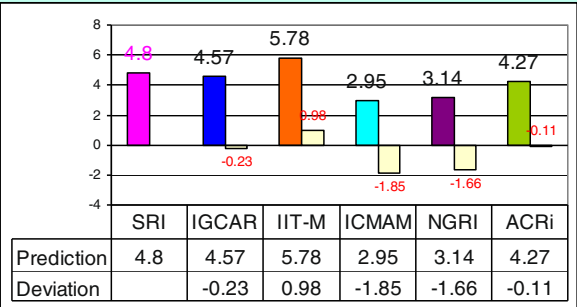

R-4 GAMMON Quarters

Figure 4. Kalpakkam site run-up measurement at standard locations and inter-code comparison. 


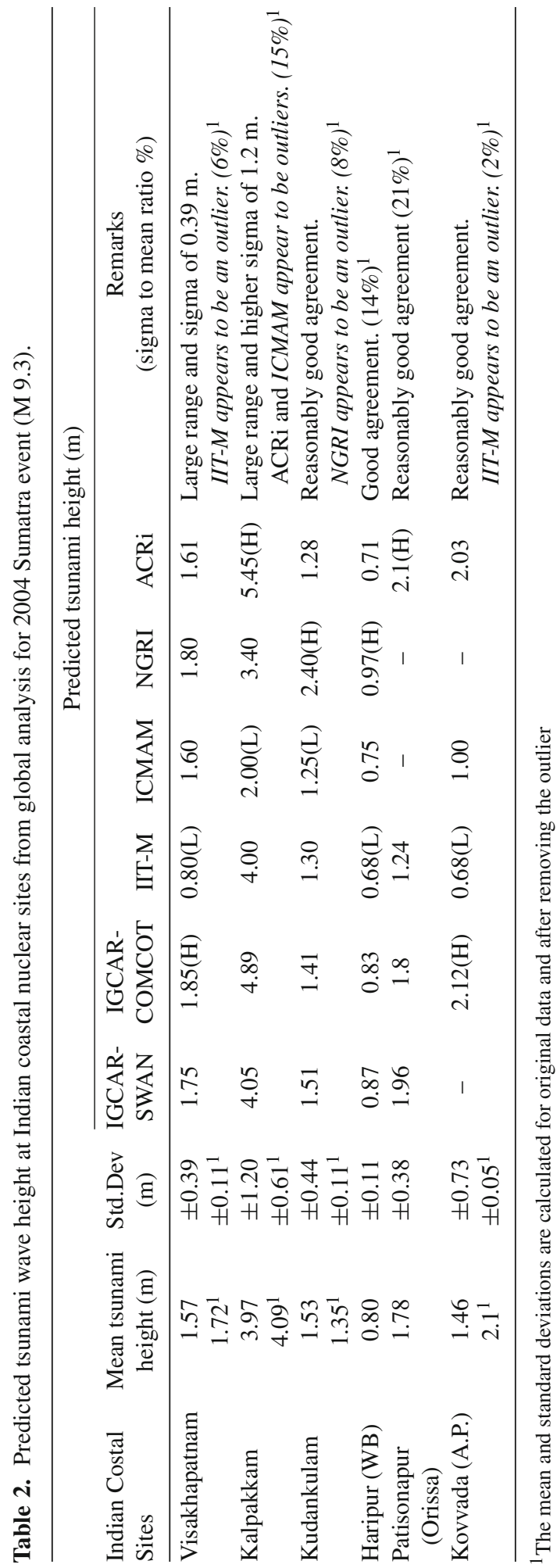




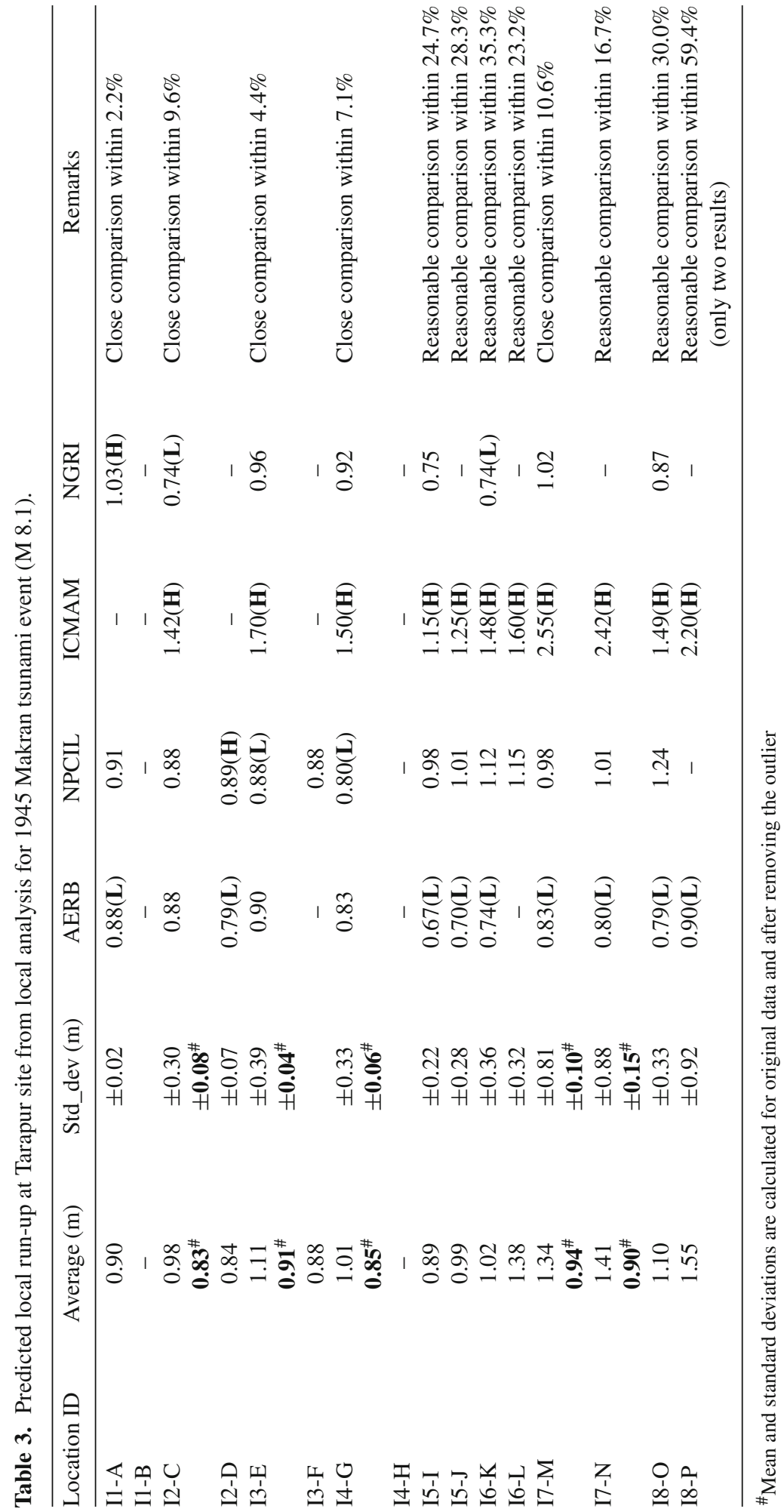


design of Indian nuclear power plants require the evaluation of run-up and the tsunami mitigation measures for the coastal plants. In case of a submarine earthquake-induced tsunami, the tsunami wave is generated within the ocean due to displacement of the seabed. The studies carried out have been effectively utilized for design and implementation of early warning system for coastal region of the country in addition to the site evaluation of Indian nuclear coastal installations. The in-house finite element code TSUSOL predictions of wave arrival time, reflections from coastal regions and run up were later confirmed by Jason satellite data (figure 2). The time signal analysis of the wave time history from in-house finite element code TSUSOL confirmed the reflections from Sri Lanka and various other Indian islands. The reflected wave periods from Sri Lanka computed as $4096 \mathrm{~s}, 2560 \mathrm{~s}$ and $1280 \mathrm{~s}$ compare well with the spectral periods of $4380 \mathrm{~s}$, $2580 \mathrm{~s}$ and $1320 \mathrm{~s}$, respectively, from the de-tided data of National Institute of Oceanography (NIO) tide gauge records (figure 3) for 2004 tsunami event. The tsunami source modelling with regard to the fault parameters, fault multiple segments and orientations were used to identify and characterize the tsunamigenic earthquakes in Indian Ocean. For inter-comparison of codes and code benchmarking, a systematic National Round Robin Exercise for detailed inundation modelling at Kalpakkam nuclear site under tsunami event of Sumatra-2004 has been carried out using a refined local bathymetry and land morphology data. Different tsunami numerical codes were used by the participants from research, academic and technical organizations. Detailed computational results of inundation reach and wave run up for Kalpakkam site have been obtained and are shown to have reasonable comparison with the post tsunami measurements carried out after the Sumatra tsunami event 2004 (table 1 and figure 4). This study also helped to arrive at the average global run-up for the present and future prospective coastal nuclear facilities along east coast as presented in table 2 for extreme event of Sumatra earthquake event of 2004.

For the Makran earthquake of 1945 (magnitude 8.1) induced tsunami event, Tarapur site has been chosen for detailed inundation and run-up study. The eastern and western halves of Makran subduction zones have different seismic patterns. The regions of western coast have very shallow
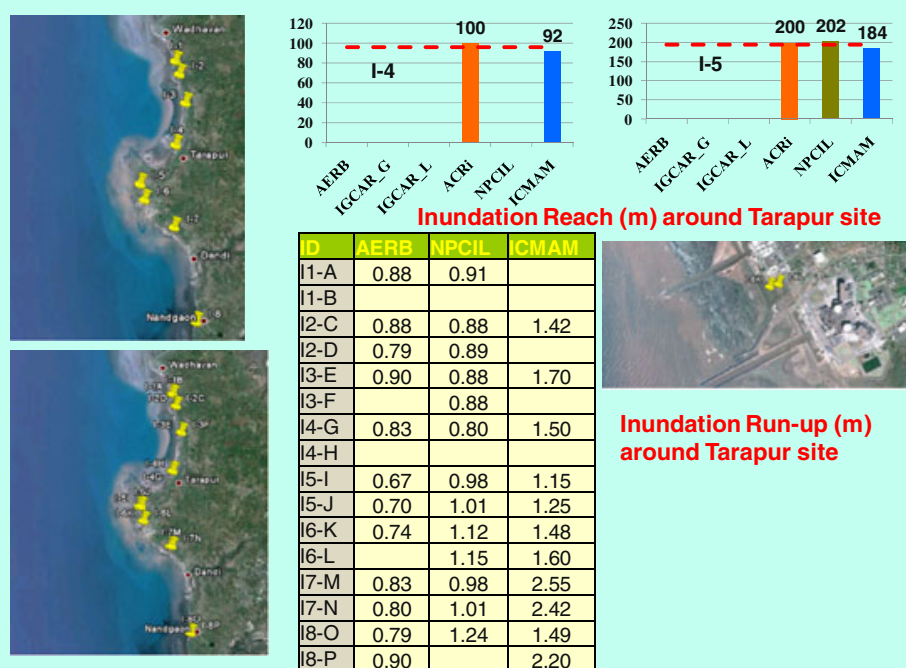

\begin{tabular}{|l|c|c|c|}
\hline ID & AERB & NPCIL & ICMAM \\
\hline I1-A & 0.88 & 0.91 & \\
\hline I1-B & & & \\
\hline I2-C & 0.88 & 0.88 & 1.42 \\
\hline I2-D & 0.79 & 0.89 & \\
\hline I3-E & 0.90 & 0.88 & 1.70 \\
\hline I3-F & & 0.88 & \\
\hline I4-G & 0.83 & 0.80 & 1.50 \\
\hline I4-H & & & \\
\hline I5-I & 0.67 & 0.98 & 1.15 \\
\hline $15-\mathrm{J}$ & 0.70 & 1.01 & 1.25 \\
\hline I6-K & 0.74 & 1.12 & 1.48 \\
\hline $16-\mathrm{L}$ & & 1.15 & 1.60 \\
\hline $17-\mathrm{M}$ & 0.83 & 0.98 & 2.55 \\
\hline I7-N & 0.80 & 1.01 & 2.42 \\
\hline I8-O & 0.79 & 1.24 & 1.49 \\
\hline I8-P & 0.90 & & 2.20 \\
\hline
\end{tabular}

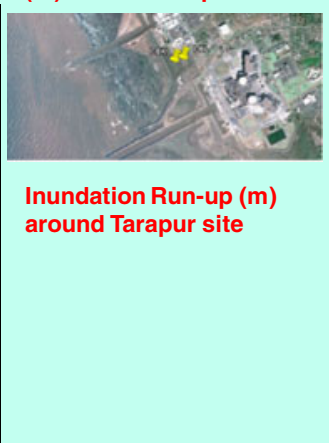

Figure 5. Local tsunami inundation reach and wave run-up at Tarapur site. 


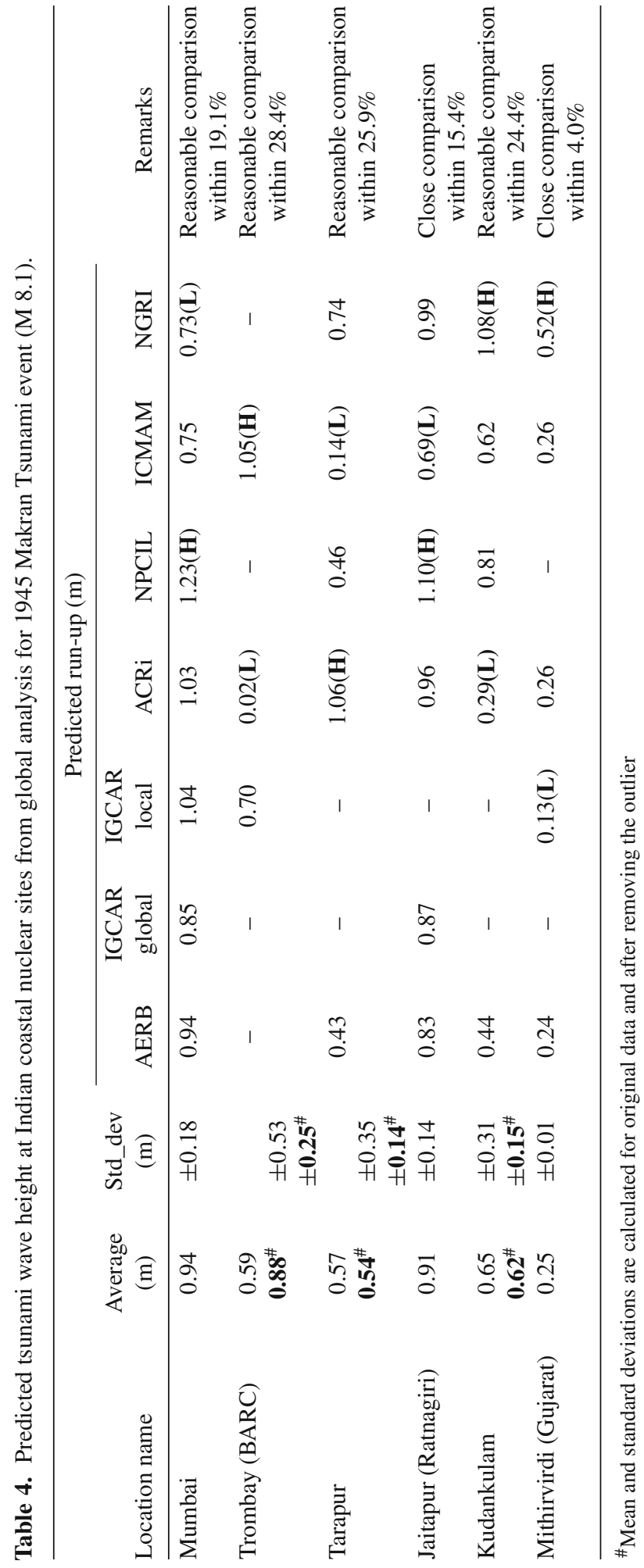




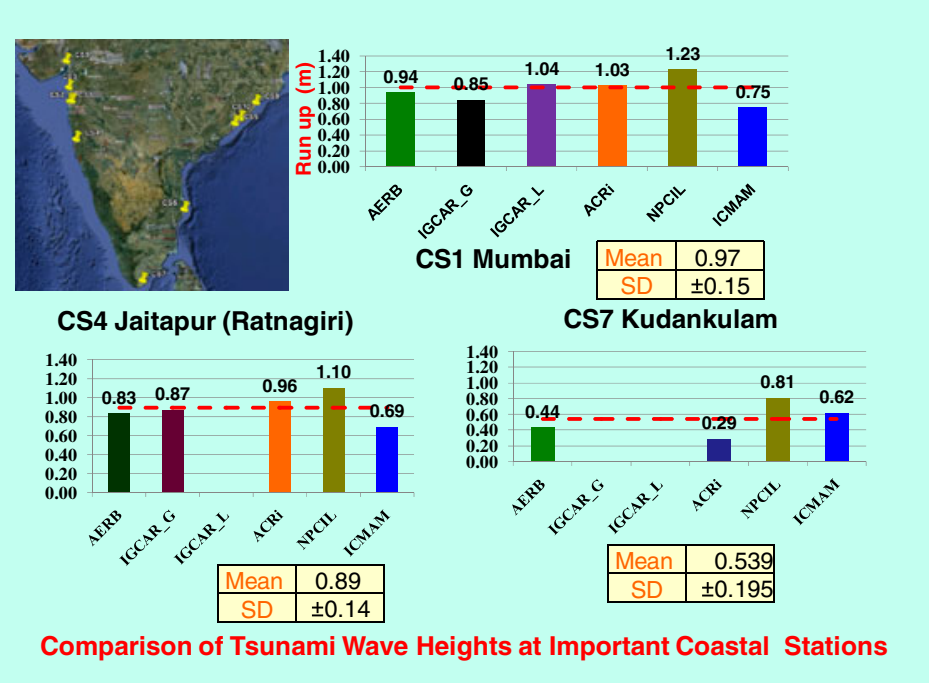

Figure 6. Global analysis of wave run-up on west coast facilities.

depths and separation between the global and local models was arrived from the modelling experience of Sumatra event. This resulted into minimization of the numerical dispersion and diffusion in the multi-grid models to capture natural physically consistent amplitude dispersion and phase dispersion for accurate inundation and run-up modelling.

The local inundation mapping was carried out with an inter-code comparison and consistent results of tsunami wave run-up were obtained at a number of important locations for Tarapur site (table 3 and figure 5), which helped to carry out a detail plant survey for TAPS-1\& 2 BWR and TAPS-3\& 4 PHWR units besides other important facilities. Again, the average global runup for the present and future prospective coastal nuclear facilities for extreme event of Makran earthquake of 1945 was in addition obtained as presented in table 4 and figure 6.

\section{Recent studies on local tsunami evaluation for Kudankulam site}

Subsequrnt to the above global tsunami analysis for eastern and western coasts and site specific studies for Kalpakkam and Tarapur sites, the recent studies have been focused for Kudankulam site by Krishna Kumar et al (2012). Kudankulam site tsunami evaluations (figure 7) have been carried out for a hypothetical earthquake of 9.0 magnitude postulated to originate at Makran Fault on the west coast and the earthquake event of magnitude 9.3 at Sumatra on the east coast. The inundation mapping and local wave run-ups for these two events are shown in figures 8 and 9 and it may be noted that Java Sumatra earthquake-induced tsunami event results in higher local tsunami run-up. The Makran hypothetical 9.0 magnitude earthquake results in maximum local run-up of $1.77 \mathrm{~m}$ (Location R1), while for Sumatra 9.3 magnitude earthquake event the maximum local run-up is $4.07 \mathrm{~m}$ (Location R1). This effect is due to the induced shadow of Sri Lanka for the Makran source for Kudankulam site, while for Sumatra fault orientation, the tsunami waves are directly focused. The location R1 is about $1 \mathrm{~km}$ from the plant site towards Kanyakumari. At plant site, the maximum wave run-up for Sumatra event is $2.76 \mathrm{~m}$ (Location R3 in 

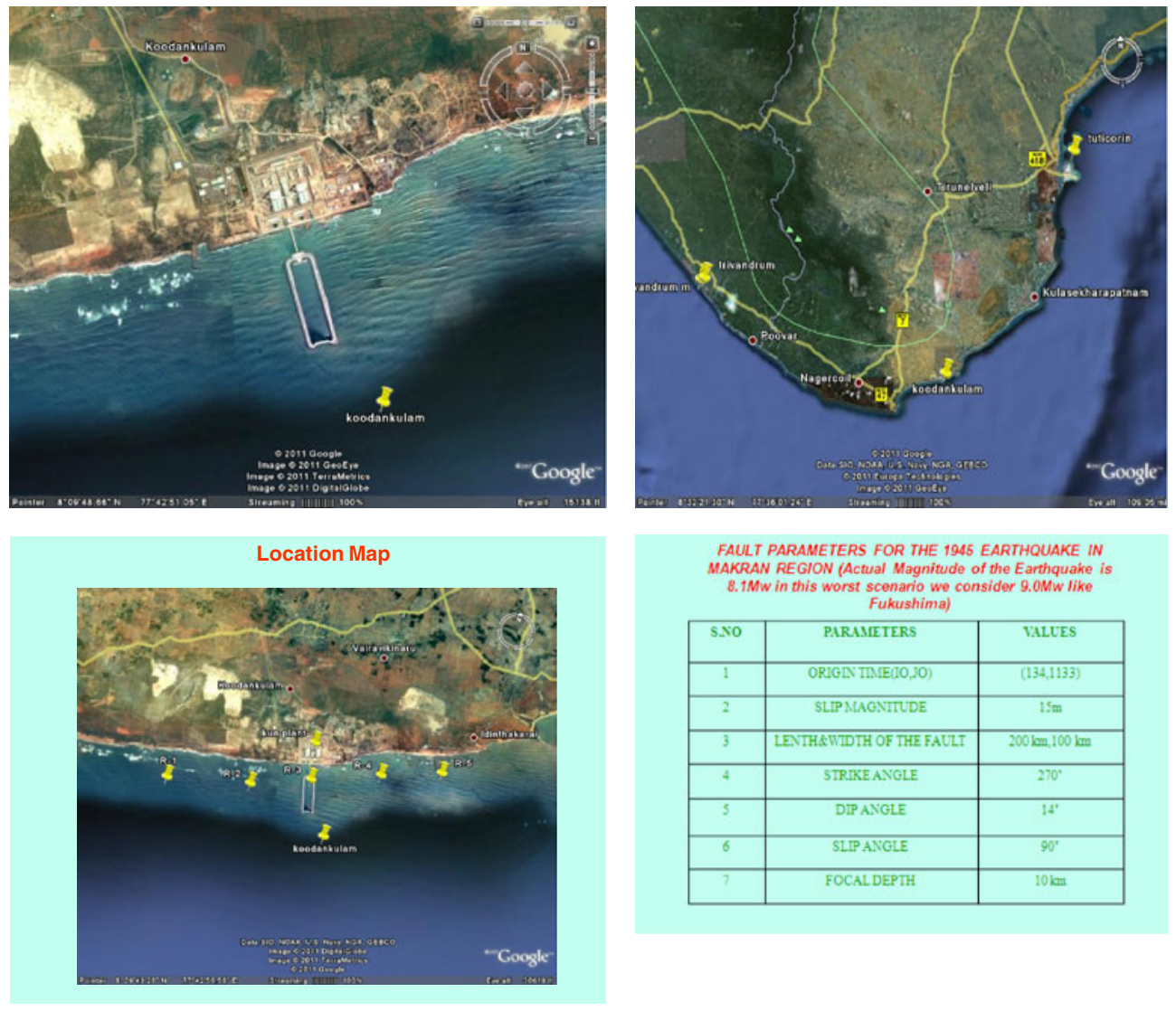

Figure 7. Local tsunami evaluation for Kudankulam.

figure 9), which is in agreement with the post tsunami observation of 2004 for this event at Kudankulam plant.

With the tsunami evaluation under extreme event category presented in this section the following are the summarized highlights:

- Intensive code benchmarking exercises resulted in validation of procedures for tsunami hazard evaluation, generation of global run-up data and local inundation data for Kalpakkam and Tarapur sites as specific example on eastern and western coasts besides global wave run-up data for new prospective sites. This has been accomplished with detail data collection for local refined bathymetry and land morphology and post tsunami survey records.

- The adequacy of National Warning System has been verified during the recent earthquake event of April 11, 2012. The local warning system at MAPS site and the site readiness have given good confidence for post tsunami management of Indian Nuclear plants.

- For the Kudankulam site computed local tsunami run-up is shown to be in good agreement with on site measurement $(\sim 2.76 \mathrm{~m})$. However, in the neighbouring locality higher tsunami run-up of $4.07 \mathrm{~m}$ is noticed.

- The tsunamigenic sources of relevance to Indian coast are located at Sumatra and Makran that are far away from Kudankulam site $(\sim 1200 \sim 1500 \mathrm{~km})$ as compared to the Pacific 


\begin{tabular}{|c|c|c|c|c|c|}
\hline \multicolumn{6}{|c|}{1945 Makran Results } \\
\hline $\begin{array}{c}\text { S.N } \\
\text { O }\end{array}$ & LOCATIONS & $\begin{array}{l}\text { LONGITUD } \\
\text { E (DD) }\end{array}$ & $\begin{array}{l}\text { LATITUDE } \\
\text { (DD) }\end{array}$ & $\begin{array}{l}\text { ARRIVAL } \\
\text { TIME (min) }\end{array}$ & $\begin{array}{c}\text { RUN-UP } \\
\text { HEIGHT } \\
(\mathrm{m})\end{array}$ \\
\hline 1 & R-1 & 77.6854 & 8.1545 & 336.75 & 1.765 \\
\hline 2 & $\mathbf{R}-2$ & 77.7021 & 8.1574 & 338.25 & 1.518 \\
\hline 3 & R-3 & 77.7139 & 8.1613 & 339.00 & 1.468 \\
\hline 4 & R-4 & 77.7274 & 8.1657 & 341.75 & 1.434 \\
\hline 5 & R-5 & 77.7393 & 8.1692 & 342.25 & 1.204 \\
\hline
\end{tabular}

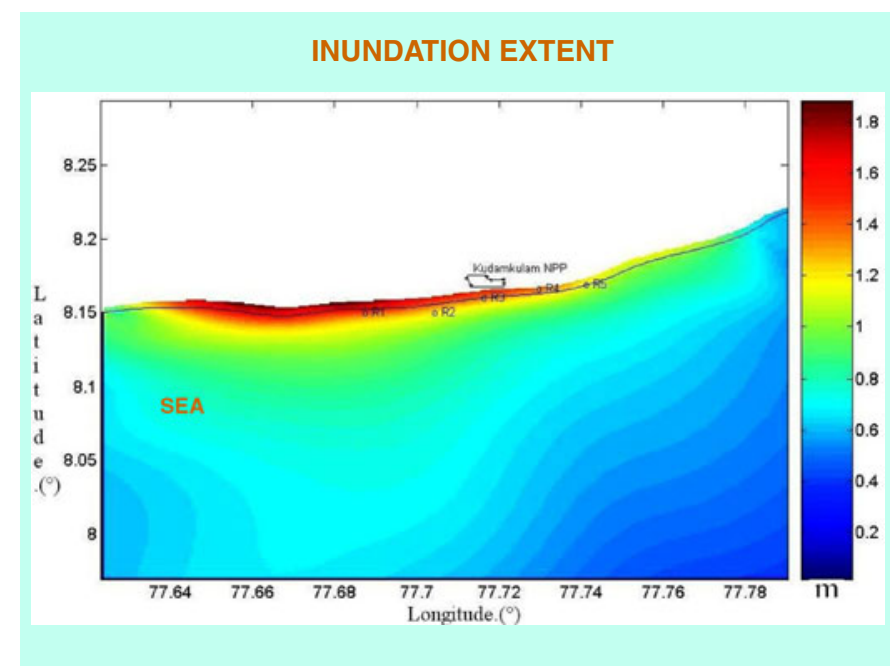

Figure 8. Results at Kudankulam site for a hypothetical M 9.0 earthquake at Makran Fault.

Tohoku Earthquake of March 11, 2011, that affected Fukushima Plants which was a near shore event. Even with extreme tsunamigenic earthquake events Kudankulam reactors are unlikely to be seriously distressed.

- In case of other sites as well, one can say that extreme tsunami events felt at Indian coastal sites are unlikely to cause any serious distress on nuclear power plants. More work however is needed in this regard.

- DAE has made a detailed assessment of external events as highlighted in the Atomic Energy Regulatory Board (AERB) Expert Group (2011) and AERB Committee Reports (2011) and National Report (2012) submitted to 'The Convention on Nuclear Safety', which describes the actions taken for Indian Nuclear Power Plants subsequent to Fukushima nuclear accident. It is once again emphasized that all the safety upgrades are in place after a thoroughcheck re-assessment of Indian Nuclear Power Plants. 


\begin{tabular}{|c|c|c|c|c|c|}
\hline \multicolumn{6}{|c|}{2004 SUMATRA RESULTS } \\
\hline $\begin{array}{c}\text { S.N } \\
\text { O }\end{array}$ & LOCATIONS & $\begin{array}{l}\text { LONGITUD } \\
\text { E (DD) }\end{array}$ & $\begin{array}{l}\text { LATITUDE } \\
\text { (DD) }\end{array}$ & $\begin{array}{l}\text { ARRIVAL } \\
\text { TIME (min) }\end{array}$ & $\begin{array}{c}\text { RUN-UP } \\
\text { HEIGHT (m) }\end{array}$ \\
\hline 1 & R-1 & 77.6854 & 8.1545 & 223.25 & 4.07 \\
\hline 2 & R-2 & 77.7021 & 8.1574 & 222.75 & 3.34 \\
\hline 3 & R-3 & 77.7139 & 8.1613 & 222.00 & 2.76 \\
\hline 4 & R-4 & 77.7274 & 8.1657 & 221.25 & 2.48 \\
\hline 5 & R-5 & \begin{tabular}{|l|}
77.7393 \\
\end{tabular} & 8.1692 & 218.75 & 2.26 \\
\hline & & & & & \\
\hline
\end{tabular}

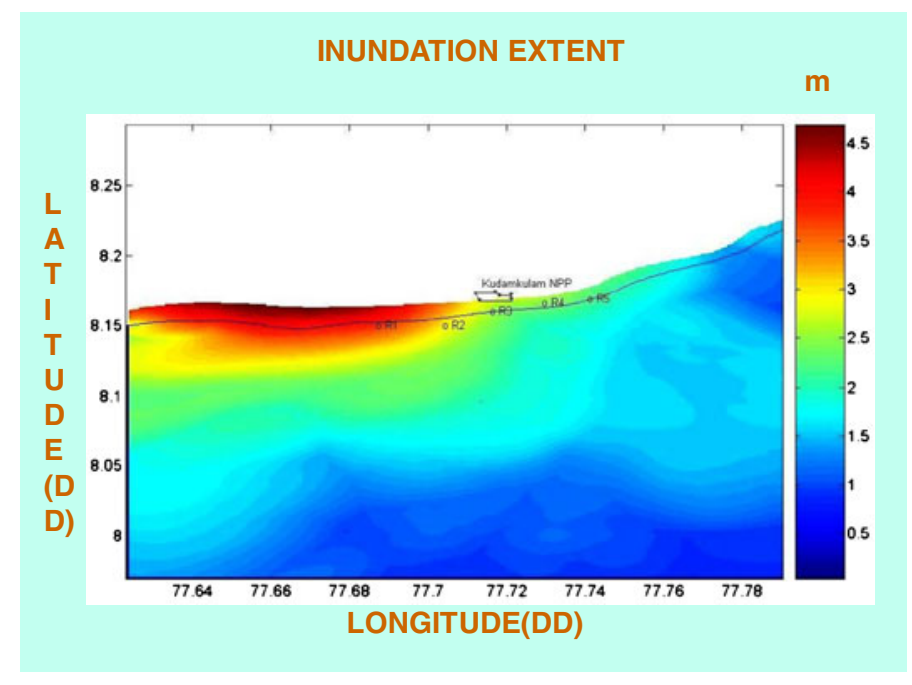

Figure 9. Earthquake of M 9.3 at Sumatra Fault and local run-up results at Kudankulam site.

\section{Indian PHWR nuclear containment safety assessment}

The beyond design basis accidents at Three Mile Island (1979) and Chernobyl (1986) created interest among the nuclear community for the safety assessment studies related to the ultimate load capacity of the nuclear containment structures to assess safety margin against release of radioactivity to the environment under an extreme event. The progression of the severe accident recently at Fukushima (2011) multiple nuclear plants has further emphasized the need for the containment integrity evaluation. Bhabha Atomic Research Centre (BARC), Trombay participated in the round robin analyses of Sandia model over-pressure test and NUPEC, Japan seismic shear wall test and in-house numerical codes were benchmarked by Singh et al (1993, 1998), Singh \& Kushwaha (1997), Gupta et al (1995), Madasamy et al (1995) and Basha 

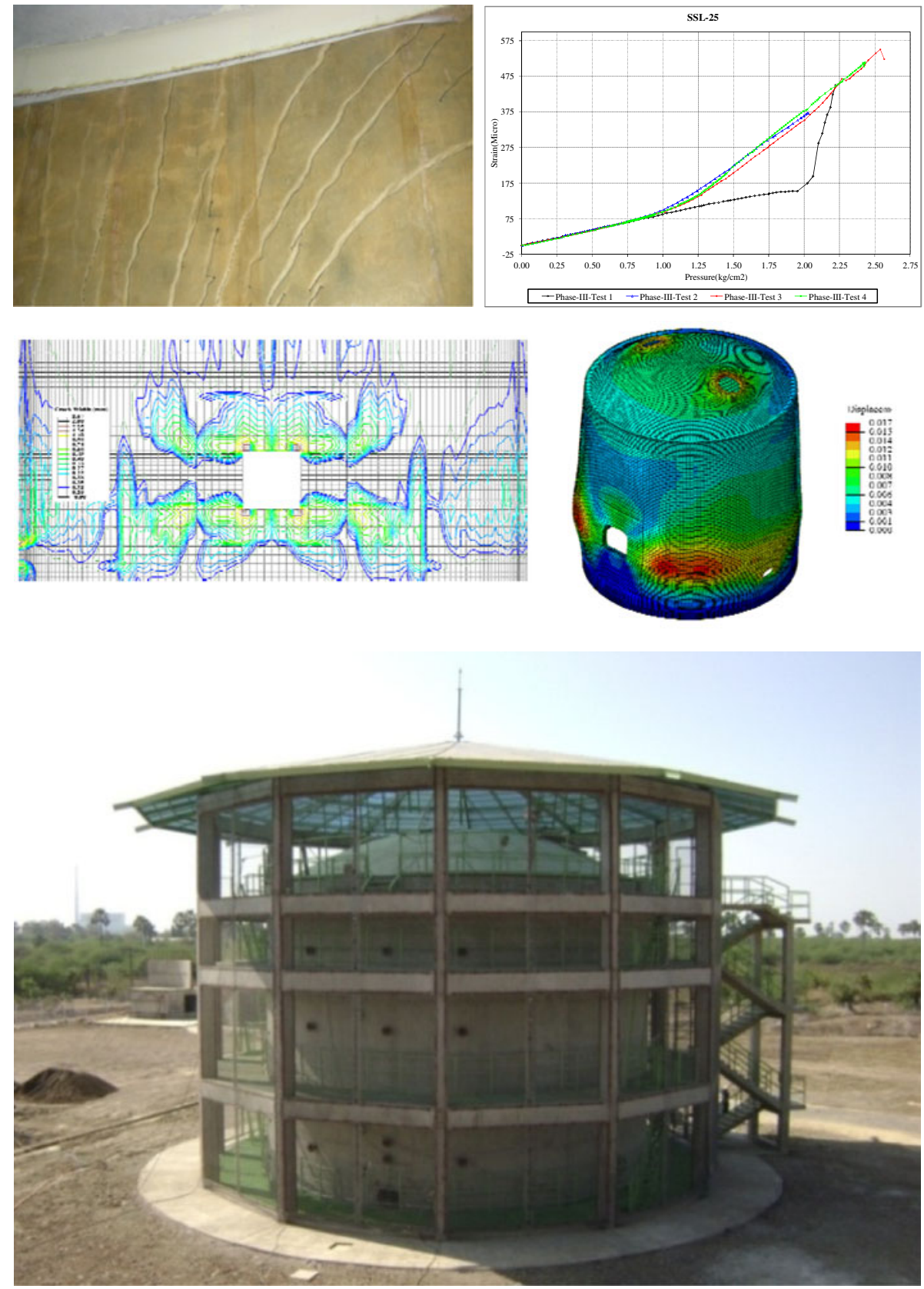

Figure 10. BARCOM test model and longitudinal and shear cracks around MAL and embedded sensor response during over-pressure tests on July 23-24, 2011 (1.78 Pd) and Oct 022011 (1.68 Pd) and numerical simulation results. 
et al (2003). For the assessment of functional and structural failure margin over the design pressure in Indian PHWR containment, a program was initiated to study the containment structural behaviour following a severe accident. BARCOM - a 1:4 scale model of pre-stressed concrete inner containment of 540 MWe Indian PHWR units at TAPS-3\&4 with design pressure (Pd) of $0.1413 \mathrm{MPa}$ was commissioned by BARC at Containment Test Facility-Tarapur (figure 10) and studies have been carried out to understand its functional and structural failure modes see eg. Singh (2009, 2011b, c) and Parmar et al (2011). Around 1200 sensors along with dataloggers have been deployed for structural response, crack monitoring and fracture parameter measurement to evaluate the local and global response of the containment test model due to overpressurization. An International Round Robin Analysis has been organized for benchmarking various inelastic numerical codes with BARCOM test data in terms of the loss of pre-stress in the membrane and discontinuity regions of major openings, first appearance of concrete surface cracks followed by first through thickness cracks, first yielding of reinforcement/tendons and significant loss of leak tightness, the maximum pressure sustained by the model before significant leakage to identify functional failure pressure of the test-model and finally the maximum static pressure sustained by the model for the structural failure analysis. All these assessments have helped to verify the predictive capability of numerical codes for integrity assessment of containment structure under over-pressurization.

\section{BARCOM functional failure phase-III over-pressure test results}

The functional failure of BARCOM under Phase-III experimental program has been successfully concluded with the structural priority test (July 2011) and leakage priority test (Oct 2011). These over-pressure tests have confirmed the BARCOM failure modes with longitudinal membrane/flexural and shear cracks that have developed and the test-data has been used to evaluate the numerical results (figure 10). The systematic review of the test-data and comparison of the pre-test results obtained from various international round robin participants has generated requisite confidence and strengthen our capabilities to analyse the nuclear containment structure due to over-pressurization under extreme conditions.

The functional failure of the BARCOM test model during the 'structurally priority test' of July 23-24 2011 up to $1.78 \mathrm{Pd}$ and 'leakage priority test' of Oct 02-03 2011 up to $1.68 \mathrm{Pd}$ in concluding Phase-III tests show the repeatability of test data (figure 10). The experiment has demonstrated that even after functional failure of primary containment, with tight cracks leakage rates are within controllable and manageable limits and shielding cover is retained. Double containment and related Engineered Safety Features further assist in controlling the ground leakage and releases to the environment. Margin against over-pressurization of BARCOM has addressed important issues with regard to containment safety under extreme events.

\section{Containment response under accidental aircraft impact}

For the extreme external event of accidental aircraft impact on containments, the assessment of 540 MWe PHWR double containment system has been carried out by Kukreja et al (2003). The nonlinear transient dynamic analysis of containment structure for Boeing 707-320 and Airbus A300B4-200 impact with simulation of cracking, crushing and rebar yielding (figure 11) leads to the following important observations:

- Outer Containment Wall (OCW) would suffer local perforation with a peak local deformation of $117 \mathrm{~mm}$ at $0.19 \mathrm{sec}$. 


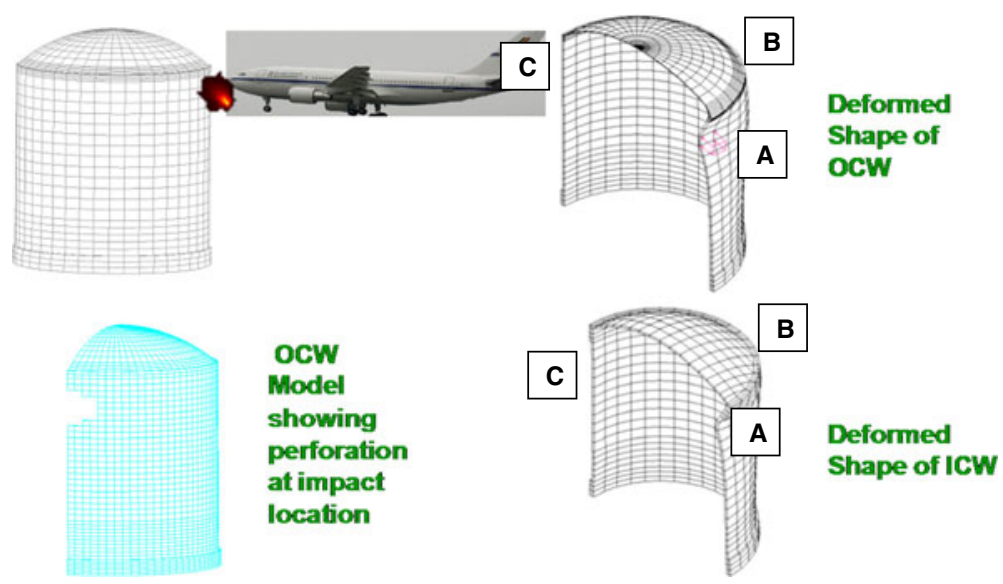

Figure 11. Scenario during commercial aircraft impact on 540 MWe PHWR double containment system.

- The stress and strain values at impact location are within the limits till $0.19 \mathrm{sec}$.

- The overall integrity of OCW structure is maintained as the displacement at point B and C (away from local impact zone 'A' of OCW) are small 5-10 mm.

- There will be localized cracking and rebar yielding in Inner Containment Wall (ICW) with maximum displacement of $115 \mathrm{~mm}$, but there would be no perforation in ICW.

- The displacements at points B and C (away from impact zone) of ICW are small 5$10 \mathrm{~mm}$.

- It is observed that the double containment system with two barriers of reinforced concrete OCW and pre-stresed concrete ICW would be capable of sustaining the full impulsive load of Boeing 707-320 \& Air Bus A300B4-200.

\section{Hydrogen deflagration/detonation studies}

For the efficient hydrogen management resulting from severe accidents within the nuclear containment system the following steps are essential:

- Estimation of explosive mixture generation with accidental release of hydrogen in air, air/steam mixture.

- Mitigation measures with development, testing and deployment of passive autocatalytic recombiners.

- Investigation of the potential hazards and its evaluation with focus on the initiating events.

- CFD simulation of the combustion process for deflagration and detonation phenomena.

- Consequence analysis with structural safety evaluation.

A massive research and development program has been initiated at BARC in Containment Test Facility (CSF) and within the Hydrogen Recombiner Test Facility (HRTF) at Tarapur. The development and implementation of Passive Autocatalytic Recombiners has been taken up for Indian Nuclear Plants. Effective design, testing and deployment of such recombiners in the containment will prevent overpressure in the containment as a result of hydrogen release as well as protect the containment atmosphere from becoming flammable under severe accident conditions (Kakodkar 2011). Out of the five steps identified above for assessment of accident sequences, the limiting 

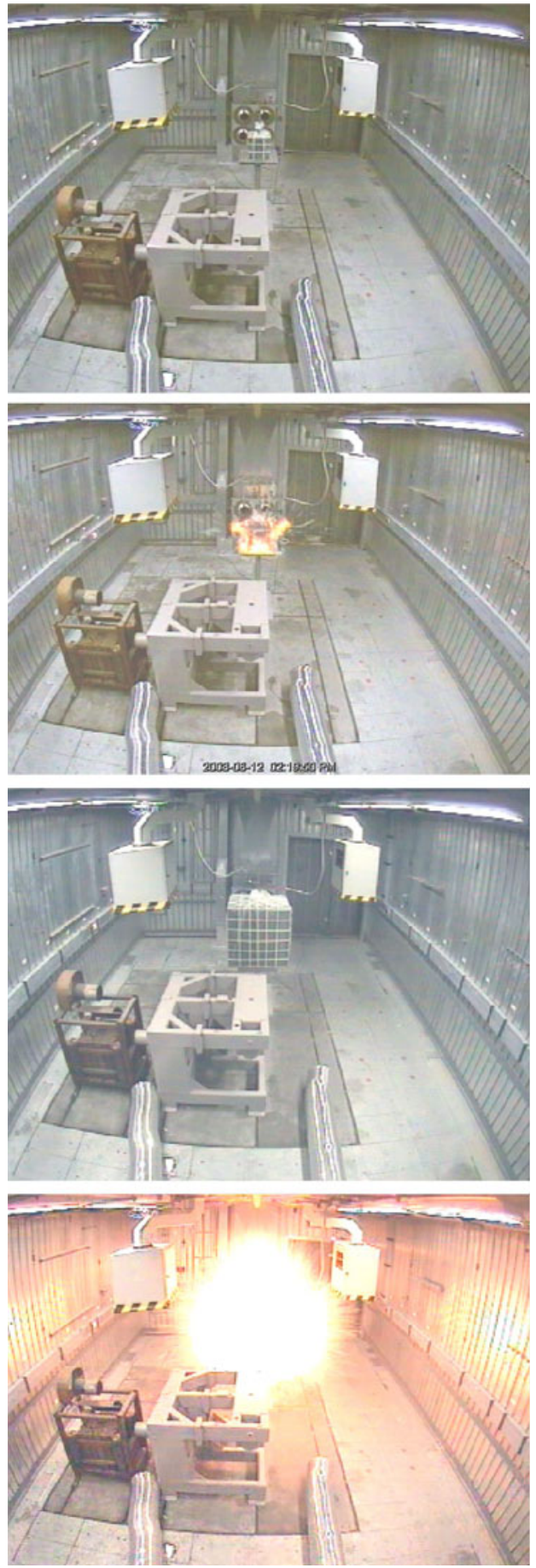

Figure 12. Hydrogen deflagration and detonation tests within structural enclosure (Singh et al 2003, 2004a, b). 
cases of hydrogen deflagration and detonation with structural safety evaluation have been carried out for hydrogen pulse characterization with an objective to evolve effective structural barriers for limiting the severe consequences.

The pulse load characterization due to hydrogen deflagration and detonation is important for the structural safety assessment with regard to distribution and combustion of hydrogen within equipments and structural enclosures. This evaluation is carried out to preclude such incidents with design measures and to mitigate and limit the consequences of hydrogen explosion. Deflagration and detonation tests have been carried out for vented and confined hydrogen explosions in controlled experiments (figure 12) and shock induced transient pressure and acceleration time histories and peak displacements (figure 13) of structural barriers are recorded to evaluate

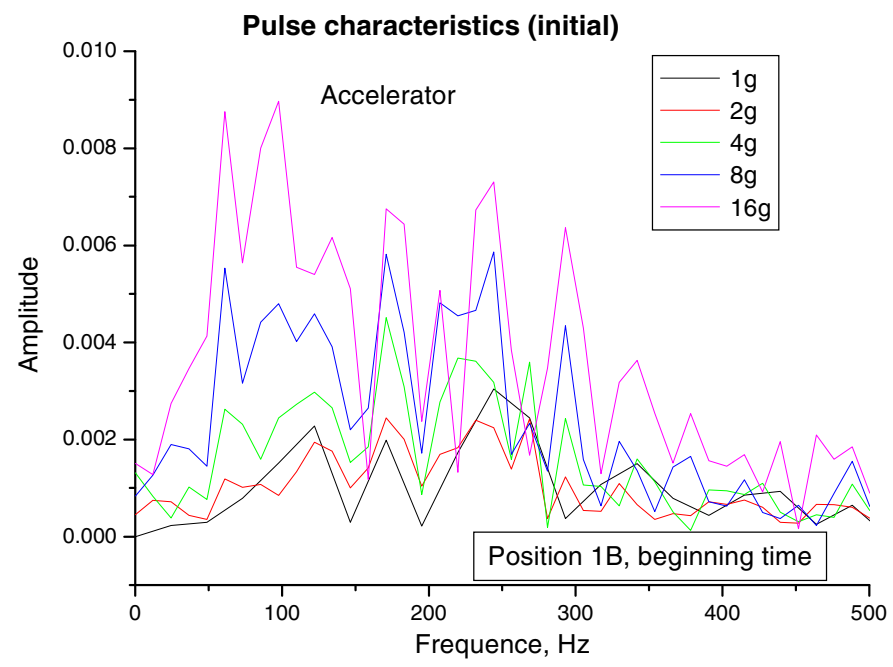

Pulse characteristics (after 24-28 msec)

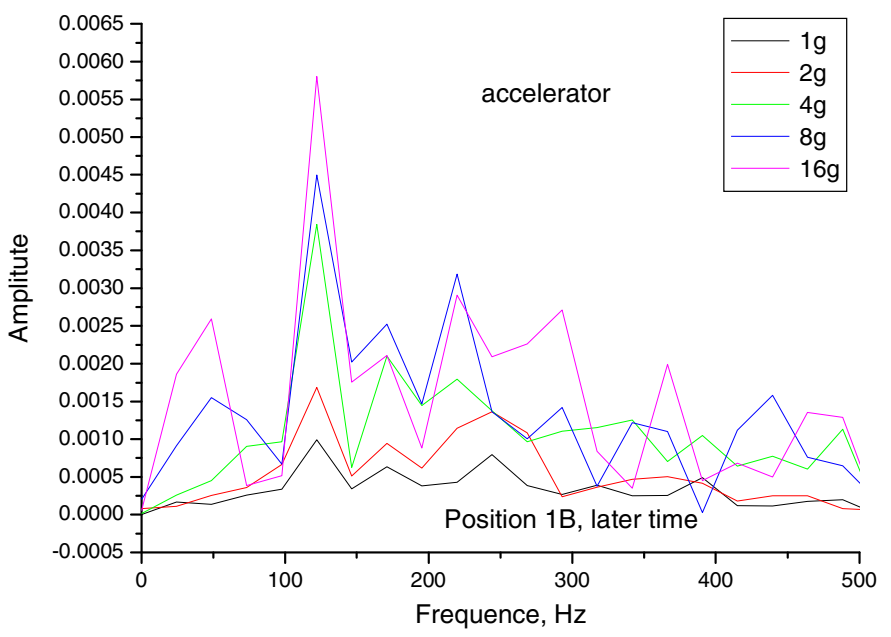

Figure 13. Hydrogen pulse records for deflagration and detonation characterization (Singh et al 2003, 2004a, b). 


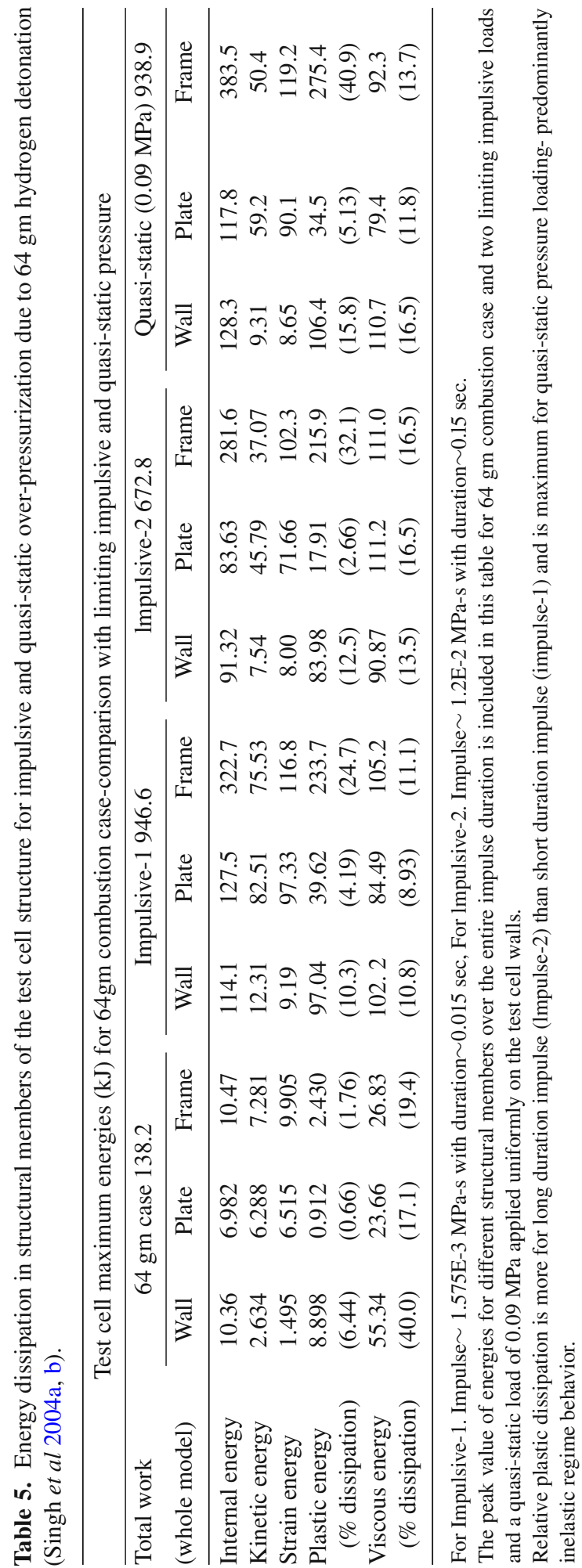


the consequences of such events by Singh et al (2003). The experimental data obtained during the hydrogen explosion tests is validated with a transient dynamic finite element analysis of the test chamber structure by Singh et al (2004a, b). A number of postulated structural failure modes such as global and local instability of the barrier plates and the frame structure, tearing or inelastic failure of panels were obtained with regard to the hydrogen combustion load (figure 14).

These studies have helped to understand the limiting impulsive and quasi-static pressure induced response and energy dissipation mechanism (table 5) for composite structural barrier systems. Further hydrogen combustion experiments planned in BARCOM test facility in the degraded cracked condition of BARCOM test model will help to understand the long term containment performance due to hydrogen combustion induced over-pressure load as was experienced in Fukushima accident. This study along with the leakage data collected in the BARCOM over-pressure experiments will be useful for an overall containment performance evaluation and evolve mitigation measures for our nuclear plants due to severe accidents.
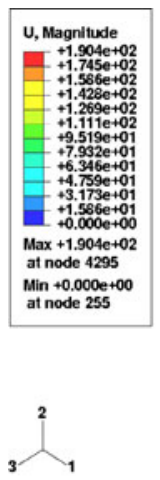
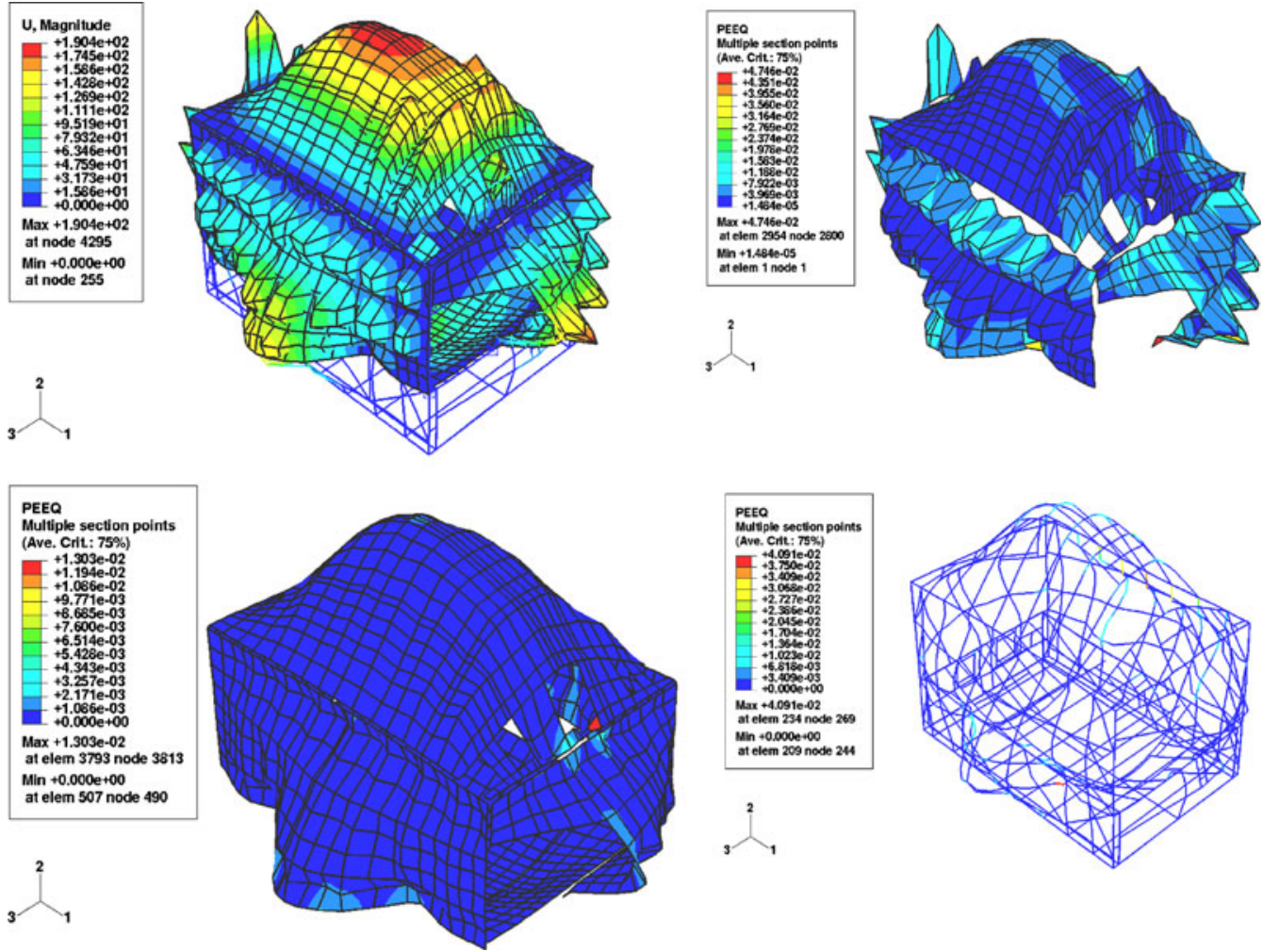

Figure 14. Test cell inelastic response for hydrogen combustion load (Singh et al 2004a, b). Maximum effective plastic strains - frame $4.09 \%$, corrugated wall $4.75 \%$, outer plate $1.30 \%$ and displacement $190.4 \mathrm{~mm}$ for the test cell due to uniform limiting quasi-static pressure $0.09 \mathrm{MPa}$ at $0.50 \mathrm{~s}$ (Singh et al 2004a, b). 


\section{Limitations of linear-no-threshold principle and resultant public trauma}

The public trauma is aggravated due to the general perception that radiation is harmful no matter how low the dose is. On the limitations of Muller's Linear-No-Threshold (LNT) principle, Calabrese (2011a, b) has cited the experimental work of Caspari and Stern (1948), which shows that at very high rate of dose the mutation rate is independent of intensity showing saturation and a threshold exists at low dose levels. Similar finding is noticed in the large scale data collected on the risk to cancer around US nuclear plants. It has been concluded that the limitations of LNT and the associated policy is costing a billions of dollars to people and is at the root of all the fear of radiation and resultant public trauma in the aftermath of events like Chernobyl and Fukushima.

Colorado, USA has a population of over 5 millions residents. According to LNT model, Colorado should have an excess of 200 cancer deaths per year but has a rate less than the national average. In Ramasar (Iran), the residents receive a yearly dose between 100-260 mSv. This is several times higher than radiation level at Chernobyl and Fukushima exclusion zone. People living in Ramsar have no adverse health effect, but live longer and healthier lives; a phenomenon often known as hormesis as described by Calabrese (2011a, b). We also know that China, Norway, Sweden, Brazil and India have similar areas where radiation level is many times higher than $2.4 \mathrm{mSv} / \mathrm{yr}$ world average.

Projected health consequences from low doses to large sections of population are questionable. In case of Chernobyl an estimate of consequences projected in 2006 was 93,000 deaths due to cancer up to the year 2056, while another estimate projected a total of 985,000 deaths till the year 2004 as described in Yablokov et al (2009). In contrast to these unsubstantiated projections of large scale mortalities that leads to fear in public mind, the actual number of total deaths as per United Nations Scientific Committee on the Effects of Atomic Radiation (UNSCEAR) 2008 report to UN General Assembly are 62 (47 plant workers, which includes 28 cases who suffered acute radiation syndrome and 15 due to thyroid cancer) and around 6000 additional thyroid cancers could be attributed to the accident.

At Fukushima it has become apparent that the evacuation from the 'Exclusion Zone' has been excessive. Some of the areas that have been evacuated probably suffered so little contamination that they could be reoccupied. As per WHO report most of the people in Fukushima prefecture would have received a radiation dose between 1-10 $\mathrm{mSv}$ during first year. At two places the doses were between 10-50 mSv, which are still below harmful level. Almost at all other places the doses were below the internationally agreed reference level for the public exposure due to radon in dwelling areas (about $10 \mathrm{mSv}$ ).

Driven by the over conservative Linear No Threshold principle, which is not substantiated by surveys in high natural radiation background areas as mentioned above, we tend to create avoidable trauma in public mind while dealing with emergency management in public domain following accidental release of radioactivity.

\section{Chernobyl psychosomatic effects}

An account of psychosomatic effects following large scale dislocation of public as given by Zbigniew Jaworowski, in WNA personal perspectives titled 'The Chernobyl disaster and how it has been understood' is reproduced below:

"Besides the 28 fatalities among rescue workers and employees of the power station due to very high doses of radiation (2.9-16 Gy), and three deaths due to other reasons, the only real 
adverse health consequences of the Chernobyl catastrophe among approximately five million people living in the contaminated regions were the epidemics of psychosomatic afflictions. These appear as diseases of the digestive and circulatory systems and other post-traumatic stress disorders such as sleep disturbance, headache, depression, anxiety, escapism, 'learned helplessness', unwillingness to cooperate, overdependence, alcohol and drug abuse and suicides. These diseases and disturbances could not have been due to the minute irradiation doses from the Chernobyl fallout (average dose rate of about 1-2 mSv/year), but they were caused by radiophobia (a deliberately induced fear of radiation) aggravated by wrong headed administrative decisions and even, paradoxically, by increased medical attention which leads to diagnosis of subclinical changes that persistently hold the attention of the patient. Bad administrative decisions made several million people believe that they were "victims of Chernobyl" although the average annual dose they received from "Chernobyl" radiation was only about one third of the average natural dose. This was the main factor responsible for the economic losses caused by the Chernobyl catastrophe, estimated to have reached $\$ 148$ billion by 2000 for the Ukraine, and will reach $\$ 235$ billion by 2016 for Belarus".

\section{Pragmatic approach to minimization of public trauma}

According to the Health Physics Society's (USA) Position Statement first adopted in Jan, 1996, and revised in July 2010, with current knowledge of radiation risks, the Health Physics Society recommend against quantitative estimation of health risks below an individual dose of 5 rem $(50 \mathrm{mSv})$ in one year or a lifetime dose of $10 \mathrm{rem}(100 \mathrm{mSv})$ above that received from natural sources. French Academy of Sciences and the National Academy of Medicine published a report in 2005 that rejected the LNT model in favour of a threshold dose response and a significantly reduced risk at low radiation exposures. Projects have been initiated by IRSN (2012) on the ecological consequences of chronic exposure to low doses following a nuclear accident.

There is thus a case for a relook at the intervention levels for relocation of public during an emergency following a severe nuclear reactor accident. This could considerably reduce the number of people to be relocated without significant increase in the risk due to radiation exposure. Combined with adequate quantitatively assessed credible margin capable of withstanding extreme conditions, such an approach can significantly minimize the fear factor and consequent catastrophe syndrome in public mind.

In view of the above observations, the following recommendations emerge:

- Realistic worst case assessment in public domain at each site taking margins beyond design basis and necessary upgradations into account. This should lead to minimization of radioactivity release under extreme events.

- Pragmatic evidence-based intervention levels (not biased by LNT) to be articulated in advance. This should minimize emergency relocation of people.

- Credibly demonstrate the best estimate impact in public domain. Expected to be much lower.

- Eventually, develop and deploy systems that do not cause any adverse impact in public domain.

\section{Concluding remarks}

Nuclear power technology has grown to a mature level with the experience of reliably supplying around a sixth of global electricity production. The economic and industrial growth in emerging 
economies coupled with constraints linked to climate change issues has put a higher demand on efficient utilization of energy resources including nuclear. Though the three severe accidents in the history of nuclear power plants all over the globe have resulted in temporary setbacks on nuclear power growth at respective points in time, the nuclear industry has learnt its lessons each time and sprung back. The response of nations to nuclear power following the recent Fukushima disaster has been a mixed one. We therefore need to address the issue of avoidable trauma and eliminate catastrophe syndrome in public mind.

The professional bodies have come forward with definite recommendations to overcome this setback see for examples recent ASME Report by Diaz Nils (2012), USNRC Report by Miller et al (2011) and NEI, INPRO and EPRI Joint Report (2012). In the Indian context, the safety assessment of Indian NPPs for internal and external events using standard benchmarks, numerical code validation and demonstrative large scale experiments has helped to establish the identified integral safety goals with confidence. Future endeavours should be directed towards better understanding of the system behaviour for improved design and safety assessment of our nuclear power plants through the three identified steps viz. (a) a defined credible limit on the extreme external events such as tsunamis and earthquakes for specific regions/sites and specification of a stringent siting criteria, (b) the necessary safety upgrades for the existing nuclear plants and robust design of new reactor systems with systematic deterministic design and safety evaluation backed up with the probabilistic assessment of nuclear reactor structures, systems and components and (c) the appropriate intervention level to minimize the public trauma and overcome the inherent limitations of the present levels, which are based on Linear No-Threshold (LNT).

Eventually, we should be in a position to ensure that:

- plant shall be able to cope without significant radioactive releases and without irreparable damage; and

- plant should be able to cope without requiring significant off-site emergency response.

With that, the important public concerns can be addressed in a scientific manner and hopefully the public confidence in nuclear power restored.

\section{Acknowledgements}

The authors thankfully acknowledge the contributions of a large number of colleagues in Bhabha Atomic Research Centre (BARC), Nuclear Power Corporation of India Limited (NPCIL) and Atomic Energy Regulatory Board (AERB), national and international participants in the round robin exercises, Task Forces, Committees and Working Groups and experts in the academic and technical organizations, who have contributed on different aspects of earthquake/tsunami evaluation and containment assessment under extreme accidents besides the safety assessment of Indian reactors.

\section{References}

AERB Committee Report 2011 Safety of Indian nuclear power plants against external events of natural origin. AERB, Niyamak Bhavan, Anushaktinagar, Mumbai 400094, Aug 2011, pp 1-117

AERB Expert Group Report 2011 Design of nuclear power plants for extreme natural events, to review external events in relation to safety of nuclear power plants. AERB, Niyamak Bhavan, Anushaktinagar, Mumbai 400094, June 2011, pp 1-99 
Basha S M, Singh R K, Patnaik R, Ramanujam S, Kushwaha H S and Venkat Raj V 2003 Predictions of ultimate load capacity for pre-stressed concrete containment vessel model with BARC Finite Element Code ULCA. Annals of Nuclear Energy 30(4): 437-471

Bodansky D 2004 Nuclear energy, principles, practices and prospects, 2nd Edition, NY: Springer Verlag

Buongio J, Ballinger R, Driscoll M, Forget B, Forsberg C, Golay M, Kazimi M, Todreas N and Yanch J 2011 May 'Technical lessons learned from the Fukushima-Daichii accident and possible corrective actions for the Nuclear Industry: an early evaluation. MIT-NSP-TR-025

Calabrese E J 2011a The LNT myth and the great fear of radiation. $21^{\text {st }}$ Century Science and Technology

Calabrese E J 2011b Fall: How a 'big lie' launched the LNT myth and The great fear of radiation 2011 Summer, pp 2-3. Interviewed by Marjorie Mazel Hecht published in $21^{\text {st }}$ Century Science and Technology

Caspari E and Stern C 1948 The influence of chronic irradiation with gamma-rays at low doses on the mutation rate. Drosophila Melanogaster. Genetics 33(1): 75-95

Diaz Nils J 2012 Forging a new nuclear safety construct. Report of The ASME Presidential Task Force on Response to Japan Nuclear Power Plant Events 2011 Fall, pp 20-27

Expert Group Report 2011 Safety of Kudankulam nuclear power and impact of its operation on the surroundings

Gupta A, Singh R K, Kushwaha H S, Mahajan S C and Kakodkar A 1995 Assessment of ultimate load capacity of inner containment for Indian PHWR. Invited Paper, Division H, SMiRT 13, Porto Alegre, Brazil

Havenaar J M, Rumyantzeva G M, van Brink W, Poelijoe N W, van den Bout J, van Engeland H and Koeter M W J 1997 Long term mental health effects of the Chernobyl disaster: an epidemiologic survey in two former Soviet regions. Am. J. Psychiatry 154(154): 1605-1607

IRSN Report IRSN/DG/2012-003 2012 Fukushima, one year later Initial analyses of the accident and its consequences

Jaworowski Z 2010 Observations on the Chernobyl disaster and LNT. Dose Response 8(2): 148-171

Kakodkar A 2011 Evolution of Nuclear Reactor Containments in India: addressing the Present Day Challenges. Thomas Jaeger Lecture, SMiRT-21, New Delhi

Kukreja M R, Singh R K, Vaze K K and Kushwaha H S 2003 Damage evaluation of 500 MWe Indian pressurized heavy water reactor nuclear containment for air craft impact. Division J, SMiRT-17, Prague

Kumar K, Srivastava K, Dimri V P and NGRI Hyderabad 2012 Private Communication

Madasamy C M, Singh R K, Kushwaha H S, Mahajan S C and Kakodkar A 1995 Nonlinear transient analysis of Indian reinforced concrete containments under impact load. Div H, SMiRT 13, Porto Alegre, Brazil

Miller C, Cubbage A, Dorman D, Grobe J and Holahan G 2011 Recommendations for enahancing reactor safety in $21^{\text {st }}$ Century, USNRC Report

National Report 2012 Actions taken for Indian NPPS subsequent to Fukushima nuclear accident to the convention on nuclear safety. Second Extraordinary Meeting of Contracting Parties

NEI, INPRO and EPRI Joint Report 2012 The way forward. U.S. Industry Leadership in Response to Events at the Fukushima Daiichi Nuclear Power Plant

Parmar R, Singh T, Thangamani I, Trivedi N and Singh R K 2011 Over-pressure test on BARCOM prestressed Concrete Containment. Paper-486, Division V, SMIRT-21, New Delhi

Sasidhar P, Singh R K and Kushwaha H S 2009 National Round Robin on Tsunami Modeling for Kalpakkam Site. DAE Committee report, BARC Restricted Report, BARC/2009/R/006

Sasidhar P, Anandan C, Singh R K and Kushwaha H S 2012 National Round Robin Exercise on Tsunami Modeling for West Coast. DAE Committee report, to appear as BARC Restricted Report, BARC/2012/R/

Singh R K 2009 Pre-test report on International Round Robin Analysis of BARC Containment (BARCOM) Test Model. ISBN: 97.8-81-8372-046-5

Singh R K 2011a Assessment of Indian nuclear coastal sites for Sumatra 2004 and Makran 1945 tsunami events. Paper-289, WS-2, SMiRT-21, New Delhi 
Singh R K 2011b Post-test preliminary report on international round robin analysis for the ultimate load capacity assessment of BARC Containment (BARCOM) Test Model

Singh R K 2011c Size effect and scalability issues of model tests addressed through fracture mechanics studies. Paper-757, WS-11, SMiRT-21, New Delhi

Singh R K 2012a Tsunami evaluation of Indian coastal NPPs and lessons learnt from extreme events. Invited Paper, International Workshop on New Horizons in Nuclear Reactor Thermal Hydraulics and Safety

Singh R K 2012b Tsunami evaluation of coastal nuclear power plants in India. IAEA International Experts' Meeting on Protection against extreme earthquakes and tsunamis in the light of the accident at the Fukushima Daichi nuclear power plant, Vienna, Austria

Singh R K and Kushwaha H S 1997 Ultimate load capacity of reinforced concrete shear wall for static and dynamic loads. Paper 597, Div H/K, SmiRT 14, Lyon, France

Singh R K and Kushwaha H S 2009 Evaluation of Indian Nuclear coastal sites for tsunami hazard. Paper1976, Division IV, SMiRT-20, Espoo, Espoo, Finland

Singh R K and Kushwaha H S 2010 Tsunami hazard evaluation of Indian nuclear coastal sites for Sumatra 2004 Event. IAEA International Workshop on External Flooding Hazard at Nuclear Power Plant Sites, Kalpakkam, India

Singh R K, Gupta A, Kushwaha H S, Mahajan S C and Kakodkar A 1993 Ultimate load capacity assessment of Indian PHWRS - Some pre test results. U02/5, SMiRT 12, Stuttgart, Germany

Singh R K, Kushwaha H S and Venkat Raj V 1998 Ultimate Load capacity of Seismic Shear walls. Proc Eleventh Symp. on Earthquake Engg, Roorkee

Singh R K, Redlinger R and Breitung W 2003 Simplified computations for BMW test-cell structure with limiting pressure impulse and response evaluations for hydrogen combustion experiments' for hydrogen combustion experiments, FZK Report, Karlsruhe, Germany.

Singh R K, Redlinger R and Breitung W 2004a Transient dynamic finite element analysis of BMW test-cell structure for hydrogen combustion load. FZK Report, Karlsruhe, Germany

Singh R K, Redlinger R, Breitung W, Veser A and Friedrich A 2004b Studies on Structural Dynamic Characteristics of BMW Test Cell during Hydrogen Combustion Experiments. FZK Report, Karlsruhe, Germany

Singh R K, Sharma P K, Ghosh A K and Kushwaha H S 2008 Tsunami Finite Element Simulation with in-house Code TSUSOL and Comparison with TUNAMI-N2 Code for national warning system. $12^{\text {th }}$ International Conference of International Association for Computer Methods and Advances in Geomechanics (IACMAG-12), Goa

Srinivasa Kumar T, Nayak S, Patanjali K Ch, Yadav R B S, Ajay Kumar B, Sunanda M V, Uma Devi E, Kiran Kumar N, Kishore S A and Shenoi S S C 2012 Successful monitoring of the 11 April 2012 tsunami off the coast of Sumatra by Indian Tsunami Early Warning Centre. Current Science 102(11): 1519-1526

Yablokov Alexey V, Nesterenko Vassily B and Nesterenko Alexey V 2009 Chernobyl: consequences of the catastrophe for people and the environment. Annals of the New York Academy of Sciences, paperback ed., Wiley-Blackwell ISBN 978-1-57331-757-3 